\title{
Determination of the Criminal Offense Elements in the Safety Rules Violation during Mining Operations
}

\author{
Olga Safargalieva ${ }^{1, *}$, Oleg Sergeev ${ }^{1}$, Yuriy Volgin $^{1}$, and Marina Agienko ${ }^{2}$ \\ ${ }^{1}$ Kemerovo state university, 650000, Krasnaya St. 6, Russia \\ ${ }^{2}$ Plekhanov Russian University of Economics, 650992, Kuznetskiy Prospect, 39. Kemerovo, Russia
}

\begin{abstract}
In the article, from the standpoint of a systematic approach, the forensic characterization of safety rules criminal violations during mining operations is analyzed. That is the basic element which determines the content and algorithm of uncovering of crimes, the investigation and trial of a criminal case. The subject (the identity of offender) is its central, basic element. It is noted that the element of subject (the identity of offender) is the most informative when investigating criminal violations of safety rules during mining operations. It is based on his study in the unity and interrelation of the following aspects: official position, social and psychological properties and personality traits and victimization behavior of the criminal offence victims and third parties. The situation of a crime (the second element of forensic characterization) is structured according to the circumstances that characterize pre-, criminal, and post-criminal state of outward things; three interrelated and interdependent are pointed out. The complex combination of the levels and edges of each selected elements of a cognizable object, due to the specifics of the crime in question, also determines the peculiarities of investigative actions and search activities at the initial stage of the investigation of safety rules criminal violations during mining operations. The article proposes recommendations to overcome the objective difficulties encountered in the investigation of criminal violations of safety rules during mining operations.
\end{abstract}

\section{Introduction}

Forensic methodology, being the final part of forensics, explores the patterns and algorithms for the investigation of certain types of crimes. The theoretical and methodological basis for the development of this section is the idea of its structure as a system consisting of three information and cognitive subsystems: forensic characterization, reflecting the system of typical forensic knowledge about criminal activity; typical forensic characterization of the preliminary investigation of certain types of crimes; forensic characterization of the trial of certain types of crimes. Forensic characterization of the

\footnotetext{
* Corresponding author: safolnik@yandex.ru
} 
crime, thus, is the basic element that determines the content and algorithm of the activities for uncovering, investigation and trial of the criminal case.

The problem of investigating criminal violations of safety rules in the conduct of mining operations is connected with the need to identify a complex of interrelated, mutually influential signs of forensic characteristics, i.e. identifying not only the elements of the traditional structure of forensic characteristics and their correlation among themselves, but a system-forming complex of features describing the features of this type of crime. It seems that the study of the forensic characterization of criminal violations of safety rules in the conduct of mining operations should be carried out from the perspective of a "system-wide approach", considering the crime as a single phenomenon, in which two main elements can be distinguished: the subject element (the identity of the offender) and the element of the environment where the crime event occurs (the circumstances of the crime), the remaining elements are mediated by these two elements.

\section{Materials and Methods}

The basis for the study of the specifics of establishing elements of a criminalistic characteristic of a crime at the initial stage of investigating criminal violations of safety rules during mining operations was the legal and regulatory sources: the Constitution of the Russian Federation, the Criminal Code of the Russian Federation, the Criminal Procedure Code of the Russian Federation, the Labor Code of the Russian Federation, establishing the criminousness of acts, defining investigation procedure, as well as departmental normative legal acts regulating the activities of enterprises conducting mining operations.

The empirical basis for the conclusions formulated in the article were: a) the materials of criminal cases; b) the results of the survey of employees of the investigative units and employees of the coal industry; c) materials of research of coal mines according to a specially developed program for studying and preventing violations of safety rules during mining operations. This program includes a wide range of issues, including the organization of coal mines, the organization of coal mining, mine design, safety rules for conducting work, the organization of labor protection, etc.

Research methods include: a) general scientific methods, such as formal-logical; system structural analysis; b) specific scientific methods, such as comparative legal; modeling method; statistical method; questioning.

\section{Results and Discussion}

The element of the subject (the identity of offender) in the event of a crime is the central concept, the basis of the criminalistic characteristics of the crime. It is the criminal who, being the "author" of the crime, influences the situation of the crime through his behavior before, at the time and after the commission of the crime and introduces changes in it driven by the peculiarities of his personality. The peculiarity of the subject of the crime under Article 216 of the Criminal Code of the Russian Federation is its special status, i.e. the subject of the crime are the managers (chief engineers, chief mechanics, site managers, etc.), as well as workers who carry out mining work and must comply with the relevant rules for their conduct [1].

The most significant factors of a subjective nature that determine or influence the current situation of the commission of a crime (in its broad sense) are:

1) the official position of the subject. The criminal behavior of an official (in the form of action or inaction) that does not properly perform his official duties ultimately leads to harmful effects in the form of destruction and traumatic consequences. It should be noted 
that representatives of all senior, middle and lower managerial positions act as subjects of criminal violations of mining regulations;

2) socio-psychological characteristics of the subject. Personality as a holistic phenomenon is a unity of biological, social and psychological elements. However, when analyzing the crime under consideration, we think it possible and rational to abstract from the biological nature of the subject. The complex of social and psychological personality traits involves, first, the study of the motives and goals of the individual, his social status, educational level, intellectual and emotional-volitional properties and qualities. Senior executives have a high educational level; developed intellectual and volitional abilities; sufficiently high social status, cherish them and strive to preserve it.

The latter circumstance often determines the motives for criminal behavior related to the non-fulfillment of their official duties to ensure safe mining operations (for example, ignoring the fact of insignificant excess of permissible methane norms in air samples and issuing permits for conducting works); after the ensuing of consequences harmful consequences they have the opportunity to make situational changes, beneficial for them.

Heads of middle and lower management have a high or medium level of education, in difficult or borderline situations, being focused on maintaining their position and providing material wealth to their family, are more likely to act as executors of orders of a higher manager than to make an independent decision; in their activities they tend to ignore some formal requirements (for example, not conducting daily briefings before blasting; failure to instruct in safety when changing the nature or area of work, etc.);

victimization behavior of the criminal offence victims and third parties. Requirements for compliance with safety regulations apply not only to officials, but also direct performers (for example, a miner who unbearably wanted to smoke in lava), and executives responsible for the proper operation of electrical equipment, elevators, ventilation, and other mining equipment.

The peculiarity of the socio-psychological characteristics of this category of subjects is the lack of volitional regulation, mainly emotional and expressive response to the surrounding reality, an insufficient level of critical assessment of their own behavior and its consequences. The behavior of victims and third parties, violating safety regulations, acts as a trigger for a criminal event, which was conditioned by the previous criminal behavior of an official. Consequently, the identification of the true circumstances of an event is possible only with due regard for the peculiarities of the behavior of all its direct and indirect participants.

In forensic science, the material situation of committing a crime in a broad sense means a system of spatial-temporal, real, climatic, industrial, domestic and other environmental conditions.

A feature of the situation of criminal violations of safety rules in the conduct of mining is its versatility and multi-element, in particular, we believe that it is a system of the following interrelated elements of the environment in which a crime event occurs:

- the structure of mining production and information about the activities of coal mines;

- the situation of the commission of crimes of this type and the main causes of accidents in coal mines;

- the situation after the commission of a crime.

The first element is a prerequisite for clarifying the contents of the others and, at the same time, for determining the investigative lead. Without examining these issues, the investigator will not be able to be conversant in the investigated crime, since the investigation of accidents at coal mines is closely related to the specifics of the coal industry and is due to the design features of the mines, their construction and coal mining technology. 
In particular, the investigator, in our opinion, should be aware of the design procedure for coal mines under construction and reconstruction, which should be carried out on the regulatory basis of such activities with a compulsory feasibility study confirming the economic feasibility and business need of their design and construction.

Technologically, coal mining in the coal mines of Kuzbass is quite favorable. However, despite the favorable conditions for mining, it is impossible not to note a number of factors that complicate coal mining and have a huge impact on the accident rate at coal mines. To such circumstances, should be attributed to the gas-rich coal seams, the tendency to rock bumps and mine waters.

The second element of the situation of criminal violations of safety rules in the conduct of mining operations is the most information-significant in the investigation: the situation of the commission of crimes of this type allows you to define the atmosphere of the crime, captured in the surrounding world. Closer look at the situation and circumstances of the crime leads to a clear understanding of what has happened, to the comprehension of the internal connections between the actions committed by the criminal will and their reflection on the outside. Such an understanding makes it possible not only to a reconstruction of a crime but also to understand the motives guiding the criminal when committing a crime.

The main, generally accepted, circumstances of the crime are the place and time. The establishment of these signs is one of the tasks of the investigation. The importance of the place and time of the crime is indicated by the fact that the legislator puts them in the first place among the circumstances to be proven (Article 73 of the Code of Criminal Procedure of the Russian Federation) [2].

The place of the incident as an element of the crime is of great forensic importance, since it serves as a source of evidence. In this study, the place of commission of these crimes is the coal mine. It is proposed to classify the division of the place of mining and the commission of criminal violations of safety regulations on the basis of production cycles, which is based on the connection between the crime scene and the place of a possible accident, depending on the nature of work at the particular place.

According to this classification feature, it is advisable to divide all places of possible commission of a crime (places of possible accidents, as a consequence of violation of the established requirements) into the following groups: a) places of cleaning works; b) the locations of the underground transport routes, intended both for the transport of people and minerals, rocks, and other materials; c) the location of the lifting vehicle; c) the location of the electric current cables; g) location of ventilation shafts.

Analysis of criminal cases, as well as questioning of employees of investigative units and coal industry workers allowed us to identify the main causes of accidents during mining operations, which were caused by criminal violations of safety rules. These reasons can be divided into several groups:

- violation of the mode of ventilation of underground workings and dust and gas regime (violation of the gas regime, insufficient control over the condition of the mine atmosphere, lack of adequate ventilation);

- non-fulfillment or inadequate execution of the technological regime within design basis on the opening, preparation of the mine field and cleaning works;

- non-observance of the main regulatory documents governing the requirements of safety regulations by workers of the mines (instructions for the safe conduct of work, job descriptions, labor discipline, etc.).

Thus, the main types of accidents in coal mines should be considered explosions, flashes and ignition of methane, coal and gas emissions, underground fires (endogenous fires, resulting from self-ignition of minerals and exogenous fires caused by external sources of heat - open fire when carelessly handling it, heating electrical wiring, etc.), rock caving, landslides, as well as the collapse of ground buildings and structures. 
The situation after the commission of a crime (the third element of the situation of criminal violations of safety rules during mining) may have minor or significant changes in relation to the original situation that arose during the commission of a crime. The consequences of a security breach may change the crime scene radically. Each crime causes changes peculiar only to it in the form of various traces, which are signs of the use of one or another method.

The variety of objects of the material situation of committing a crime correlates with the variety of traces remaining in it: an explosion, a fire, a landslide, injury by equipment characteristic signs remain in all types of accidents. Proper forensic assessment of traces allows you to create a real basis for the most rapid recognition in the initial investigative data on the case of a particular characteristic method of committing the investigated crime, even according to its individual features.

At the initial stage of the investigation, the following typical situations emerge: 1) the message about crime commission was received from the employer or after the accident, from medical institutions or the Ministry of Internal Affairs; 2) the message was received from the bodies of specialized inspections (Federal Service for Environmental, Technological and Nuclear Supervision) and the investigator has materials from the investigation of the special departmental commission.

In practice, the most common is the second typical situation when a case is initiated on the materials of a special departmental commission. In accordance with clause 1.5 of the "Regulations on the procedure for technical investigation of the causes of accidents at hazardous production facilities", approved by the Federal Mining and Industrial Supervision Directive of Russia of June 8, 1999 N 40, a special departmental commission is created to investigate the accident [3-4].

Depending on the nature and consequences of the accident, a special commission is appointed. It is appointed by a special order of the head of the territorial department of the Federal Service for Environmental, Technological and Atomic Supervision. Usually it includes representatives of this department, the state labor inspectorate, trade unions, the administration of the enterprise where the accident occurred and the medical staff (if there are injured workers).

In addition, the commission may employ specialists in various fields of knowledge to carry out calculations, examinations, analyzes and other actions necessary to form the conclusions of the commission [5-6]. The results of a special technical investigation are documented by an act to which other documents are attached: an inspection report of the accident site, acts in a special form (form H-1) for each victim, plans for the site of the accident, explanations of eyewitnesses of the incident, medical reports for each victim, etc.

When formulating a conclusion and drawing up an act of technical investigation, the commission should answer three groups of questions:

- technical and organizational causes of the accident;

- conclusions about the persons who are guilty of the accident;

- measures for the conduct of restoration work and the prevention of such accidents.

The materials obtained allow the investigator to understand the situation and the nature of the incident and to decide whether to initiate or refuse to initiate criminal proceedings. However, it should be noted that a special departmental commission conducts its investigation without complying with the norms of criminal procedure law and without applying forensic methods, in connection with which its materials are significantly different from materials obtained during the preliminary investigation.

Moreover, In many cases after the liquidation of the accident and the completion of the commission's work, the situation at the scene changes completely or partially, due to objective reasons, its original form does not remain, which makes it difficult to forensic investigate the scene of the accident and ultimately negatively effects on the results of the 
investigation. We believe that the following recommendations will help minimize such negative effects, as the inspection of the crime scene by the investigator together with the departmental commission [7-8]. Unfortunately, this recommendation has a limited scope of activity: this method cannot be applied in a situation of persistence of a dangerous situation at the scene. The commission's activities at the scene under such circumstances are excluded. Forensic analysis of departmental investigation materials, which allows defining a system of tactical tasks and planning the main areas of preliminary investigation at the stage of initiating a criminal case.

One of the main objectives of the forensic analysis of the initial information embodied in the special technical investigation act is the analysis of the validity of the conclusions of the special commission on the cause of the accident. After conducting such an analysis, the investigator may conclude that: the cause of the accident, indicated in the conclusion of the technical investigation, is confirmed; the cause of the accident is not confirmed; in addition to the causes of the accident specified in the act, there are others; Commission incorrectly identified the circle of persons responsible for the causes of the accident. Only after the investigator analyzes the submitted materials of the technical investigation and decides on the soundness of the conclusions made by the special departmental commission, he can use the information contained in these materials when deciding whether to initiate or refuse to initiate criminal proceedings.

The first typical situation (the message came from the employer himself, after the accident that happened, from medical institutions or the Ministry of Internal Affairs) is less common in practice. The first situation has two subspecies. It develops in the event of a fatal accident. In accordance with Article 228 of the Labor Code of the Russian Federation [9], the prosecutor's office must be notified immediately and the received message should be immediately checked up. Based on the results of the check, a decision is made.

The situation of the scene of the incident may persist or be subject to minor changes but information about the essence of the incident, the liable and guilty persons is very scarce, or not available at all.

It is advisable to start the investigation with an investigator inspecting the site of the incident, seizing and examining documents describing various aspects of activities to ensure the safety of mining operations, the forensic medical examination of the living and corpses, questioning witnesses of the event; at large- scale traumatic consequences and the work of a special departmental commission, mutual coordination of plans and actions is necessary.

Second, the subspecies (when the victims received non-fatal injuries and enter the medical institution) suggests the following sequence of actions: the medical institution informs the bodies of the Ministry of Internal Affairs, which respond to the scene and carry out an initial check, then the materials are transferred to the Investigation Committee.

The investigation is significantly complicated by the following circumstances: a significant period of time (a month or more) passes from the moment of the incident; the situation at the scene is not preserved; Ministry of Internal Affairs staff poorly represent the specifics of these crimes, are not familiar with the methods of their investigation, therefore the quality of the inspection materials sent to the prosecutor's office is low, which subsequently creates many difficulties in analyzing information and deciding whether to initiate criminal proceedings.

In our opinion, it is advisable to begin an investigation in such a situation by taking and examining documents describing various aspects of the work to ensure the safety of mining operations, questioning witnesses of the event; the forensic medical examination of the living, the appointment of forensic engineering, technological and other types of expertise. 


\section{Conclusion}

The basis for establishment of facts of a criminal violation of safety rules during mining operations based on a study of the material situation of a crime can be such investigative actions as inspecting the scene of the crime, seizure and examining documents describing various aspects of activities to ensure the safety of mining operations, the forensic medical examination of living and corpses, forensic engineering, technological and other types of examinations.

Often after the liquidation of the accident and the completion of the commission's work, fully or partially, the situation at the scene of the crime, due to objective reasons, changes its original appearance. In order to ensure that we receive the most complete information about a crime event, we consider it advisable to recommend:

- the inspection of the scene by the investigator together with the departmental commission. Unfortunately, this recommendation has a limited scope of activity: this method cannot be applied in a situation of persistence of a dangerous situation at the scene. The commission's activities at the scene under such circumstances are excluded.

- forensic analysis of departmental investigation materials, which allows defining a system of tactical tasks and planning the main areas of preliminary investigation at the initial stages of the criminal case.

\section{References}

1. Criminal Code of the Russian Federation, Ed. from 12.27.2018 (Russian Newspaper, Moscow, 2018)

2. Criminal Procedure Code of the Russian Federation, Ed. of 06.03.2019 (Russian Newspaper, Moscow, 2019)

3. Labor Code of the Russian Federation, Ed. from 27.12.2018 (Russian Newspaper, Moscow, 2018)

4. Resolution of the Gosgortekhnadzor of the Russian Federation of 08.06.1999 N 40 "On approval of the Regulations on the procedure for technical investigation of the causes of accidents at hazardous production facilities" (Russian Newspaper, Moscow, 1999)

5. M. Agienko, A. Naumov, I. Gaag, Yu. Volgin, IOP Conf. Ser.: Mater. Sci. Eng., 41, 04046 (2018)

6. V. Shelestukov, V. Erin, G. Pavlov, IOP Conf. Ser.: Mater. Sci. Eng., 41, 02029 (2018)

7. J. Balzano, Wash. Univ. Glob. Stud. Law Rev., 12, 00560 (2004)

8. D. M. Uhlmann, Univ. Mich. Law Sch. Rep., 4, 191-201 (2015)

9. M. Agienko, Yu. Volgin, E. Moroz, T. Olofinskaya, IOP Conf. Ser.: Mater. Sci. Eng., 41, 02030 (2018). 